\title{
AVOIDABLE VASCULAR SPREAD IN RESECTION FOR BRONCHIAL CARCINOMA
}

\author{
BY \\ JOHN A. AYLWIN \\ From the Thoracic Surgical Department, The General Infirmary at Leeds
}

(RECEIVED FOR PUBLICATION JUNE 18, 1951)

Changes in technique have been a recurring feature in the development of pneumonectomy. Although it is 17 years since the first successful resection, and the operation can now be regarded as safe for the patient, there still remain unsolved problems, particularly those connected with long-term results, and the adaptation of surgical method to specific types of disease. In bronchial carcinoma an important principle of cancer surgery was applied when radical intrapericardial resection was devised (Allison, 1946), and deriving from this operation special attention was given to the block dissection of cancerous lymphatics; thereafter considerable improvement was promised in the prospects of patients with bronchial carcinoma. At present, however, most series show that five-year survivals occur in little more than one in ten patients after resection, and these results are among the worst of all of cancers treated by surgical removal.

By the end of 1949, 111 pneumonectomies for carcinoma had been done in the Thoracic Surgical Unit at Leeds, and Table I shows how few of these patients remain

TABLE I

Analysis of Results of 111 Pneumonectomies One Year After Last Resection $(1940-49)$

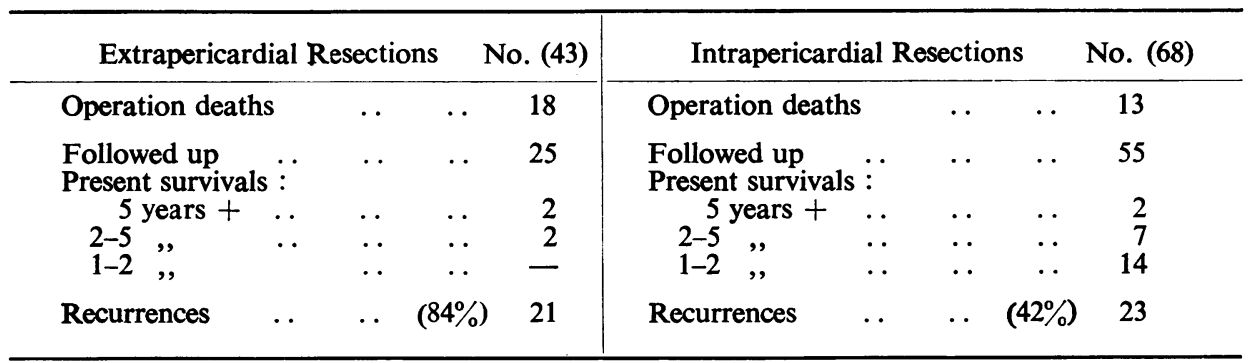

alive. Equally disturbing are some indications that, although intrapericardial resection has reduced the incidence of local recurrence, it is not altering ultimate survivals to the extent that might be expected from such an advance in treatment, and the search for further technical improvement is important if surgery is to play a reasonable part in the treatment of this common cancer.

Retrospective examination of the Leeds series has led to the belief that more practical attention might be paid to the role of the pulmonary veins in the spread 
of carcinoma to the rest of the body. The recognition and control of lymphatic spread, now largely accomplished in reasonably early cases, are exposing a further cause of surgical failure in the form of vascular dissemination (Fig. 1), which is occurring in a high proportion of otherwise successful results.

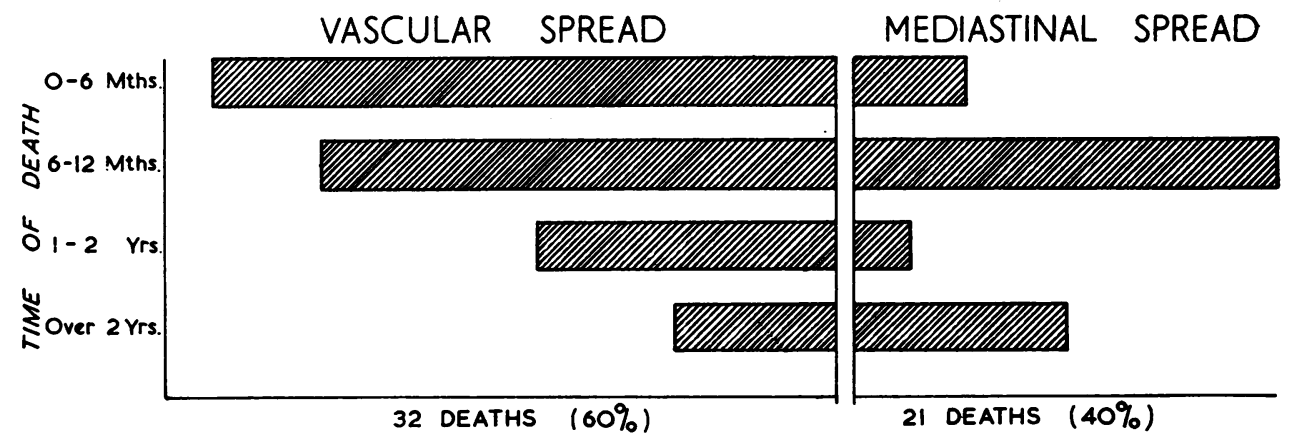

FIG. 1.-The high incidence of vascular compared with mediastinal spread at death after resection.

The principle of primary vein ligation when removing a tumour with vascular invasive properties has been applied for a long time in other parts of the body, but has received scant attention in the surgery of bronchial carcinoma. In the past, it has been usual to tie the pulmonary artery first, but the reasons given for this (Rienhoff, 1947) can be regarded as no longer valid.

Only a few gross vascular erosions have been obvious in tumours of this series, but smaller ones have been detected frequently on detailed examination; and, in this type of case, post-operative vascular spread appears almost invariably. Veins have been found containing a soft mixture of neoplasm and thrombus, and fragmentation must be inevitable during the manipulations required for pneumonectomy. When spread has not already occurred, tying the veins before disturbing the tumour will eliminate probable dissemination that can be avoided, with a corresponding improvement in results. Whilst there is no proof for the fatalist view that all vascular spread is pre-operative in origin, there is a strong case for believing that malignant tissue may be released into the circulation during operation, so a serious trial of this modification in technique is indicated, though no reference to it has been found in the literature.

\section{The Frequency of Post-operative Vascular Metastases}

After operation $60 \%$ of the patients under review died with evidence of bloodborne metastases, and it was decided to determine what effect resection had on their occurrence. Two other series were chosen for comparison: one group consisted of patients treated by radiotherapy palliation, when the disease was apparently limited to the chest, but was unsuitable for surgery ; the second, based on necropsy figures of Willis (1948), was chosen to show the base-line incidence of such spread when the disease runs its natural course. The result was striking, and in Table II it is seen that after pneumonectomy vascular dissemination has been reduced by only $12 \%$ below the $72 \%$ necropsy figure, and radiotherapy has produced no signi- 
TABLE II

Contrasted Incidence of Vascular Spread at Death

\begin{tabular}{|c|c|c|c|c|}
\hline & Treatmen & & Vascular Deposits & Assessment \\
\hline $\begin{array}{l}\text { Untreated } \\
\text { Radiotherapy } \\
\text { Pneumonectomy }\end{array}$ & $\begin{array}{l}. \\
\ldots \\
.\end{array}$ & $\begin{array}{ll}\ldots & \ldots \\
. & \ldots \\
. & \ldots\end{array}$ & $\begin{array}{l}(82 \text { cases) } 72 \% \\
(37 \text { cases) } 70 \% \\
(53 \text { cases) } 60 \%\end{array}$ & $\begin{array}{l}\text { Necropsy } \\
\text { Clinical } \\
\text {,, }\end{array}$ \\
\hline
\end{tabular}

ficant reduction at all. This implies a serious criticism of any form of radical surgery unless part of the spread is preventable. Patients developing recurrence after operation usually die at home without necropsy, so the $60 \%$ incidence of vascular spread in this group does not include silent metastases undetected by out-patient investigation, and the true state may be even nearer to the necropsy figure.

\section{Evidence OF Microscopic InVASION OF Veins}

Goldmann (1897) first described microscopic bronchial malignant tissue within the pulmonary veins; Simpson (1929) found 24 thrombosed veins in 139 bronchial carcinomas (18\%) ; Fried and Buckley (1930) published some excellent pictures of the same process in association with cerebral metastases ; and Boyd (1930) showed malignant emboli in the centre of distant metastases. Willis (1934) emphasized the frequent occurrence of the carcinomatous invasion of veins with associated distant spread.

Old slides from 58 resected carcinomas in the Leeds series were found suitable for examination using a microscope with a mechanical stage, and in some cases there were several slides from each specimen for detailed study. A criterion of "vascular invasion" had to be laid down, and that chosen was "permeation by malignant cells through all coats at least as far as the intima." On these grounds $40 \%$ of the specimens showed cancer cells in contact with the blood returning to the heart. (Incidentally $80 \%$ of these patients died with widespread vascular deposits.) This pathological material was not the most suitable for this type of investigation, for it is customary in taking sections to include an area of normal tissue in the block, and the veins available in these slides were usually those most recently exposed to malignant invasion. Examples are shown in Figs. 2-6. The next step was to start a systematic search on recent specimens in which the whole lung was available. By careful dissection, veins were opened branch by branch through the tumour, looking for rough or firm white areas on the intimal surface ; a diagram of this was kept, and sections taken for microscopic assessment (Fig. 7). By this method positive results are being found much more readily, and the true state of potential spread seems much higher than the $40 \%$ indicated by the old slides, and more in keeping with the $60 \%$ incidence of vascular spread observed by clinical follow-up.

\section{Gross INTRAVASCULAR EXTENSIONS}

It is not always necessary to use a microscope to find intravenous tumour in resectable carcinomas. Sliced specimens have sometimes shown unsuspected masses projecting into large veins. In some cases the invasion is so near the heart that it 


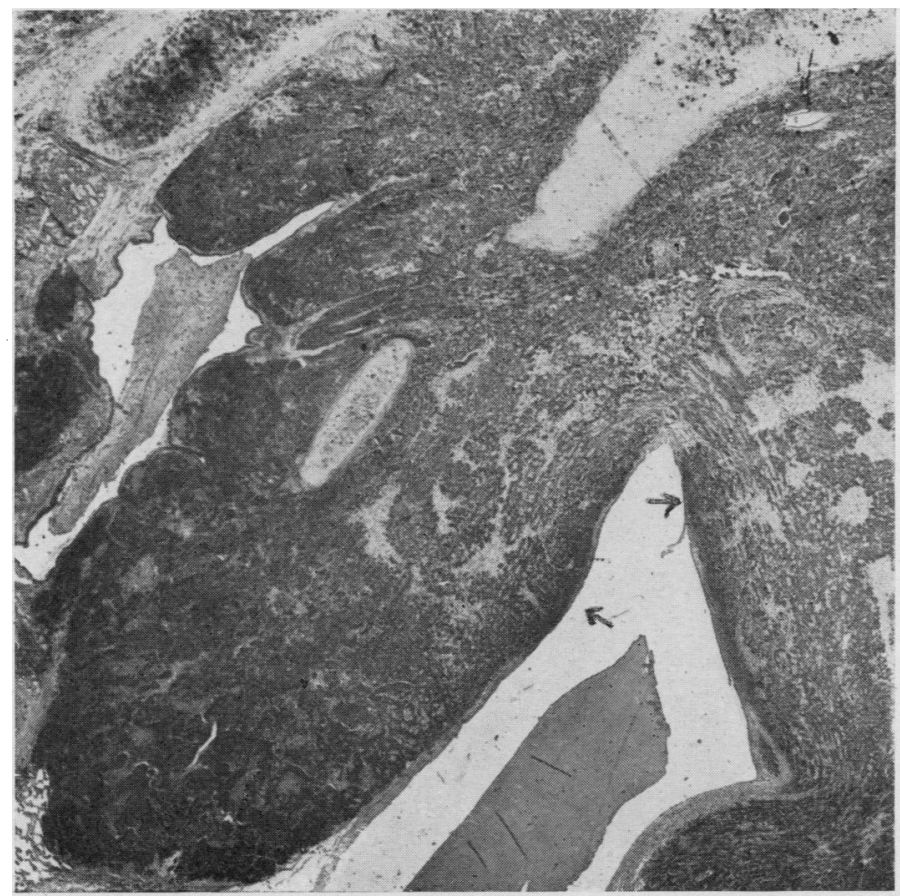

Fig. 2.-Erosion of a medium-sized vein.

FIG. 2

Fig. 3.-Polyp of tumour and thrombus in a large vein.

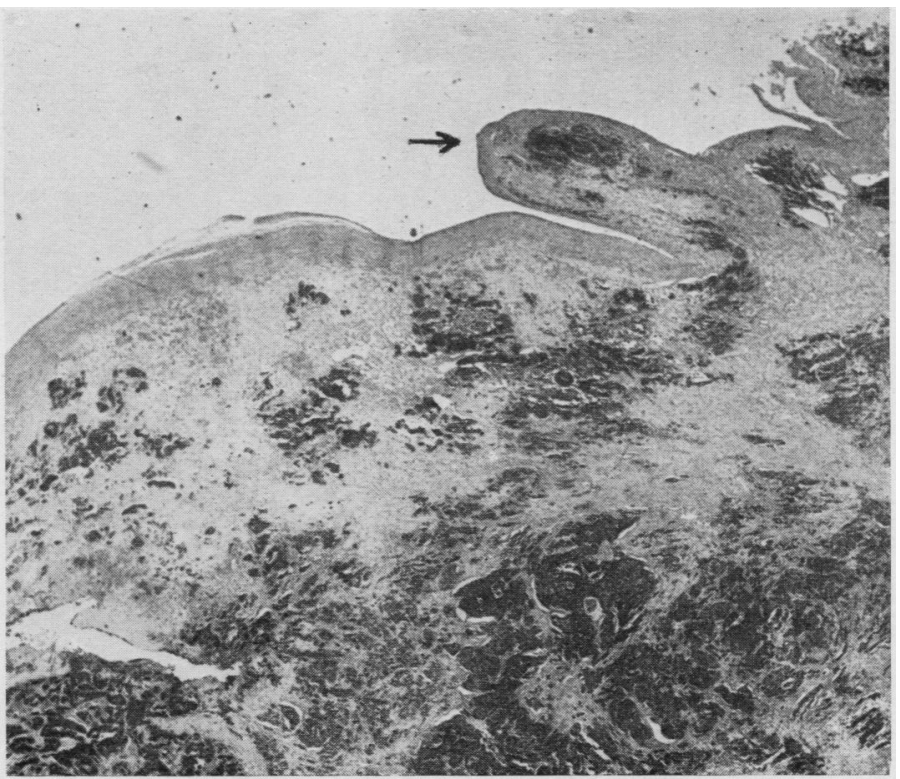

FIG. 3 
Fig. 4.-Destruction of part of an inferior pulmonary vein near the left auricle (L.A.).

Fig. 5.-Small vein containing malignant strands and organizing thrombus.

FIG. 6.-Intimal surface of an eroded vein.

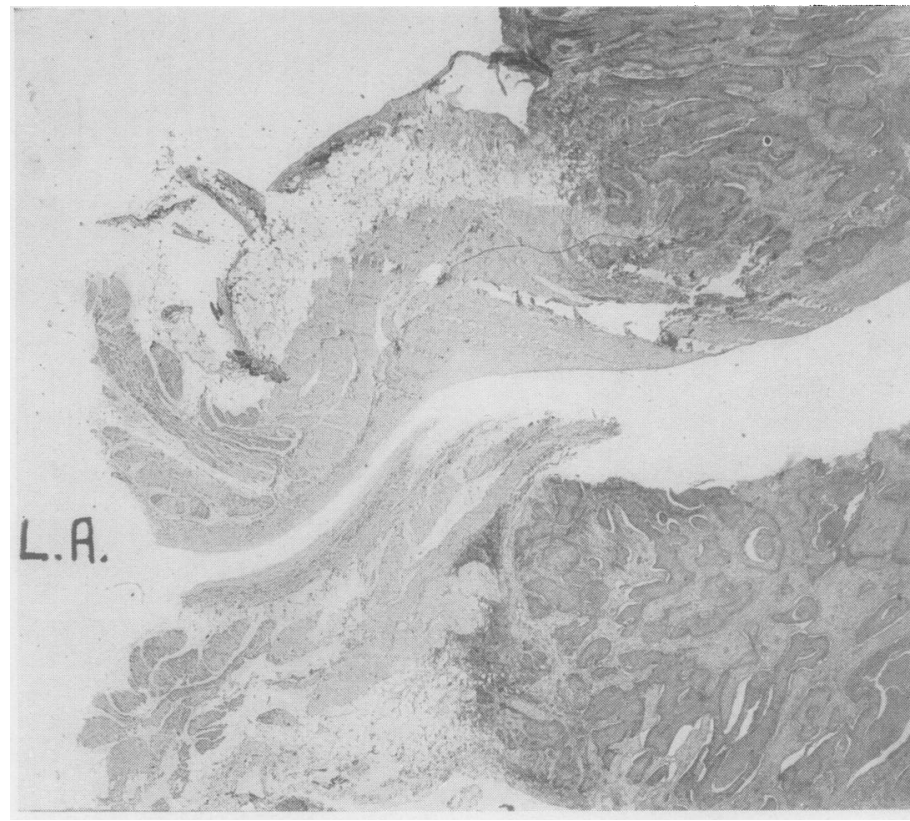

FIG. 4

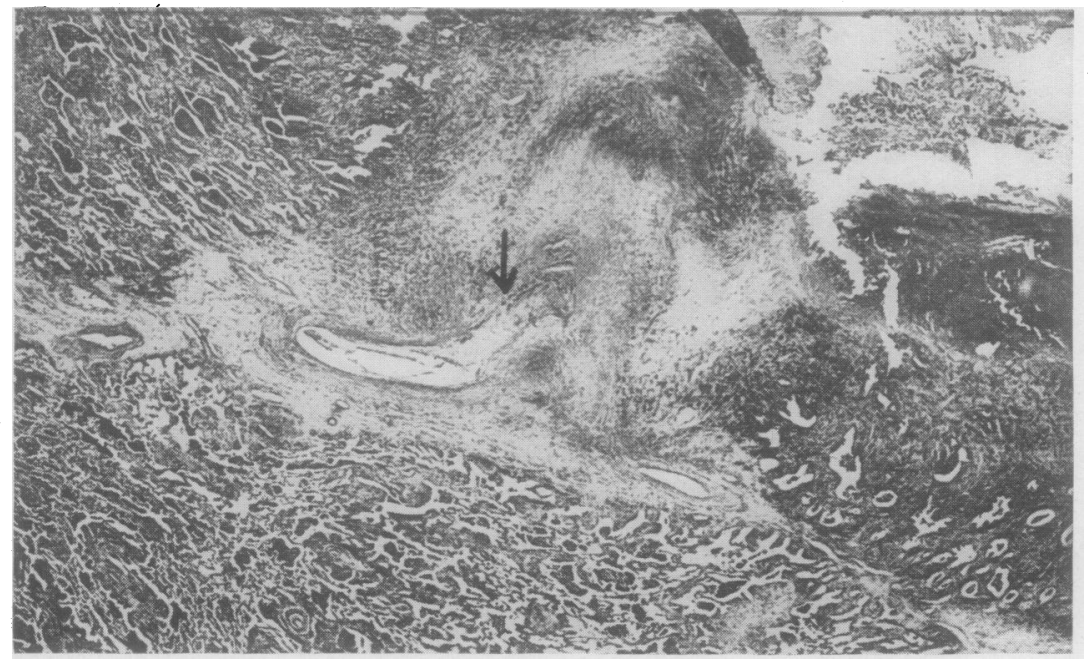

FIG. 5

FIG. 6

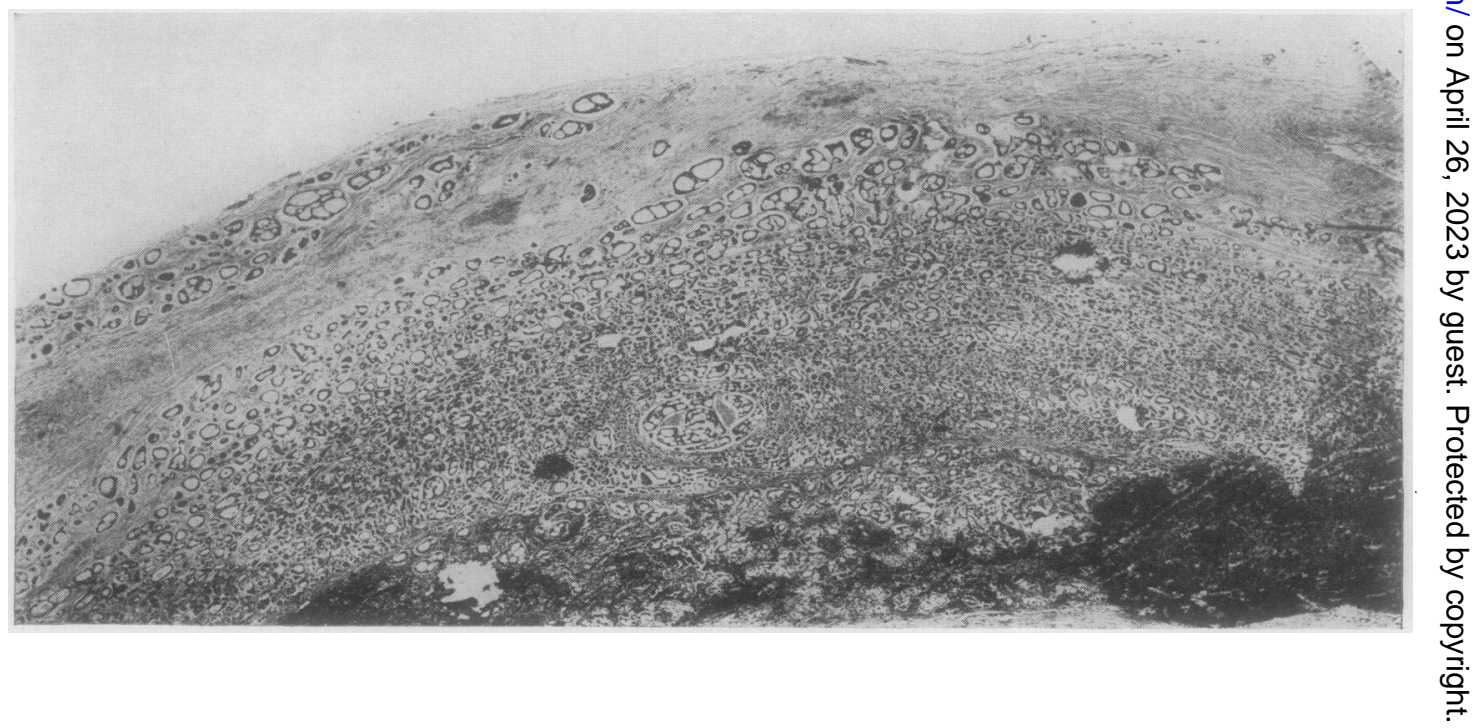




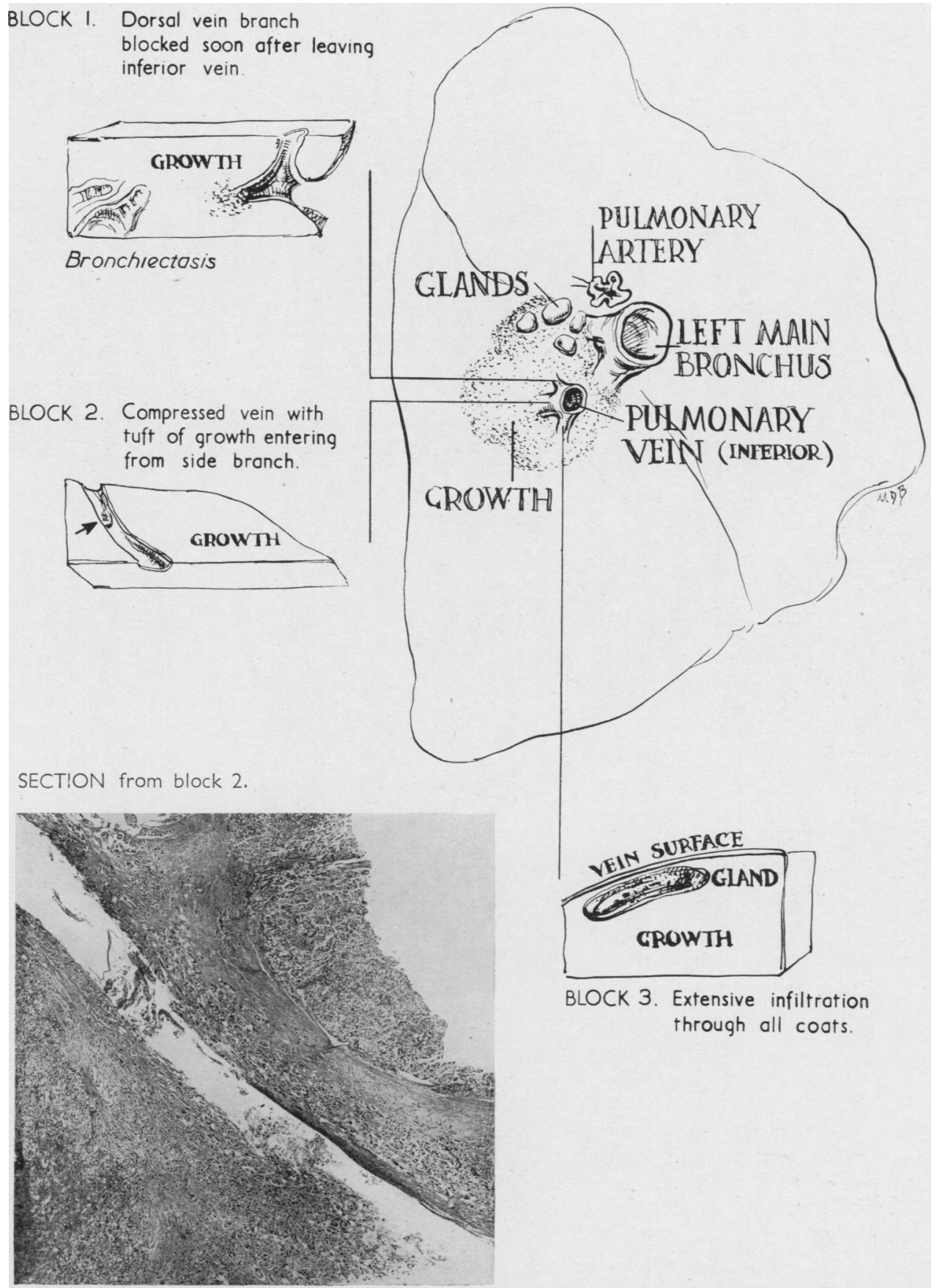

Fig. 7.-Scheme used for demonstration of vein erosion in recent specimens. 


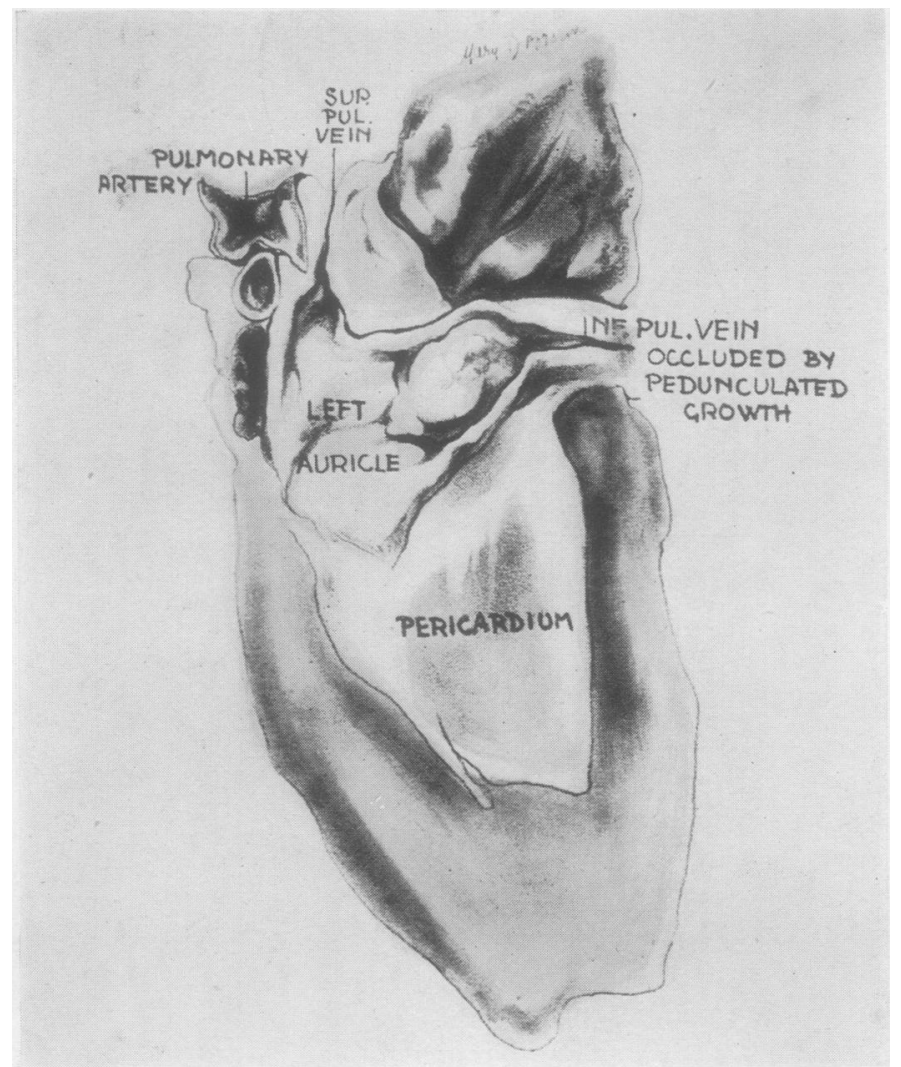

Fig. 8

Fig. 8.-Tumour fungating. into the left auricle.

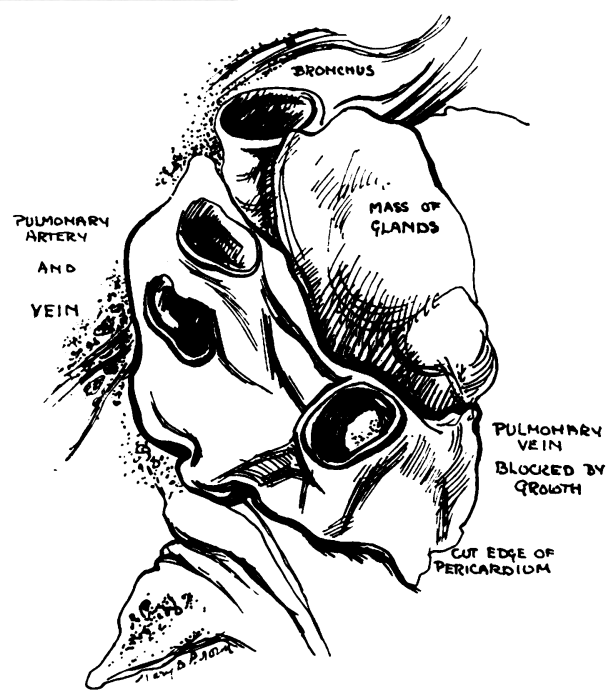

FIG. 9

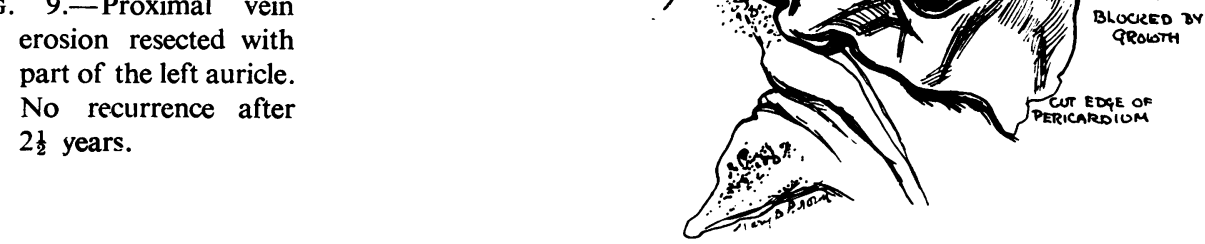

No recurrence after $2 \frac{1}{2}$ years. 


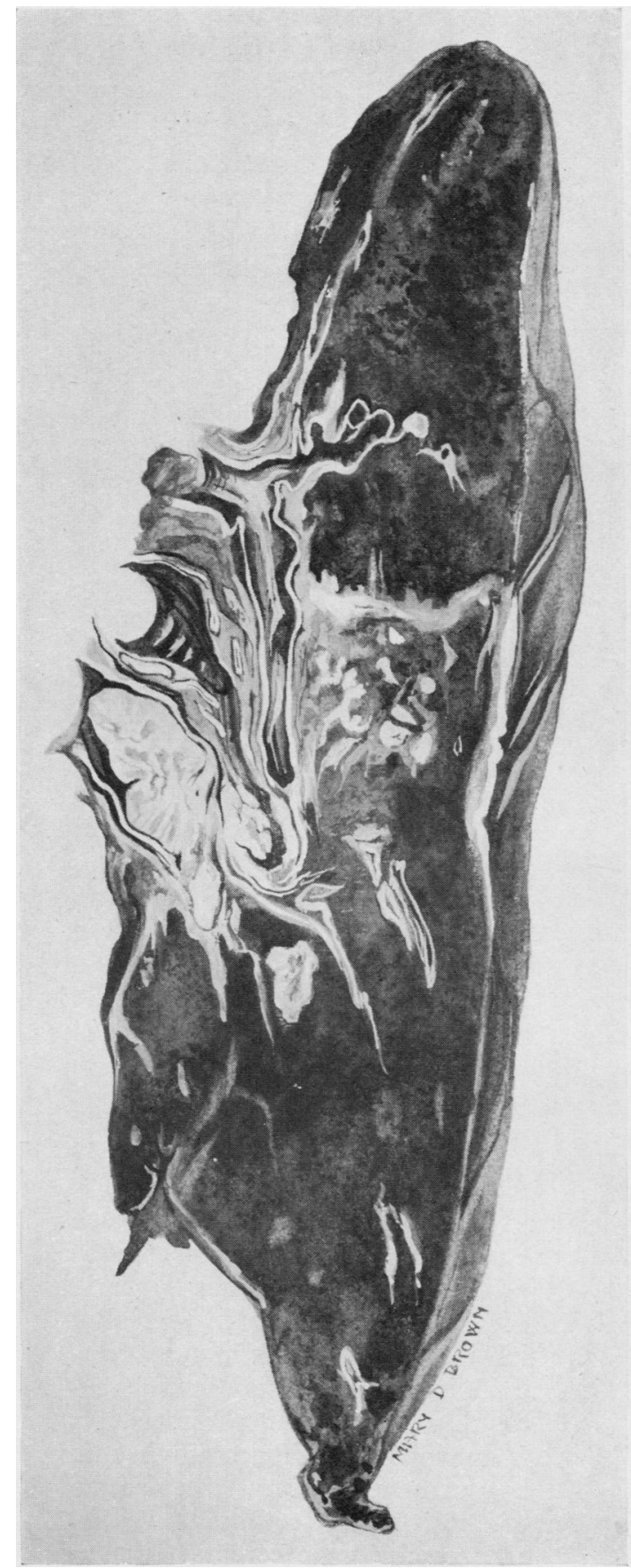

FIG. 10.-Resection with immediate ligation of inferior vein blocked by tumour mass.

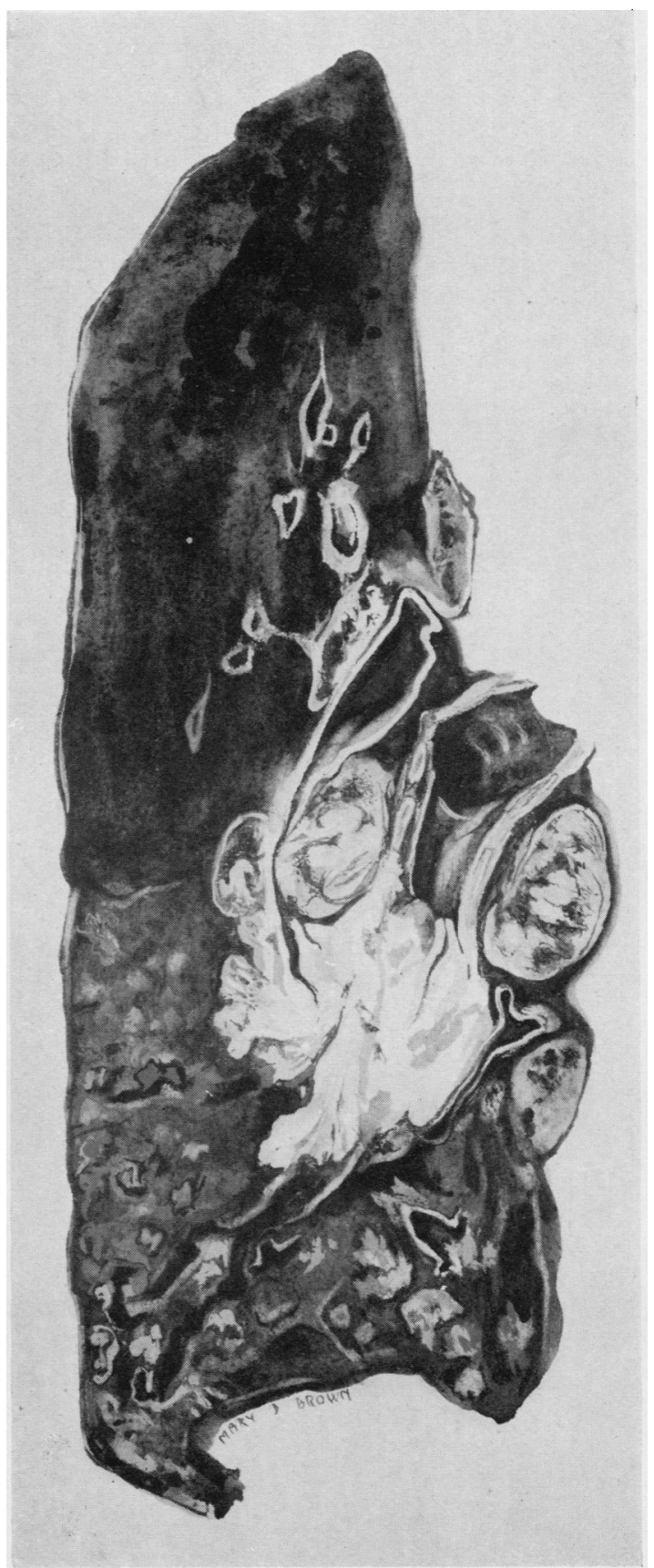

FIG. 11.-Concealed vein erosion without primary vein ligation. Widespread recurrences. 


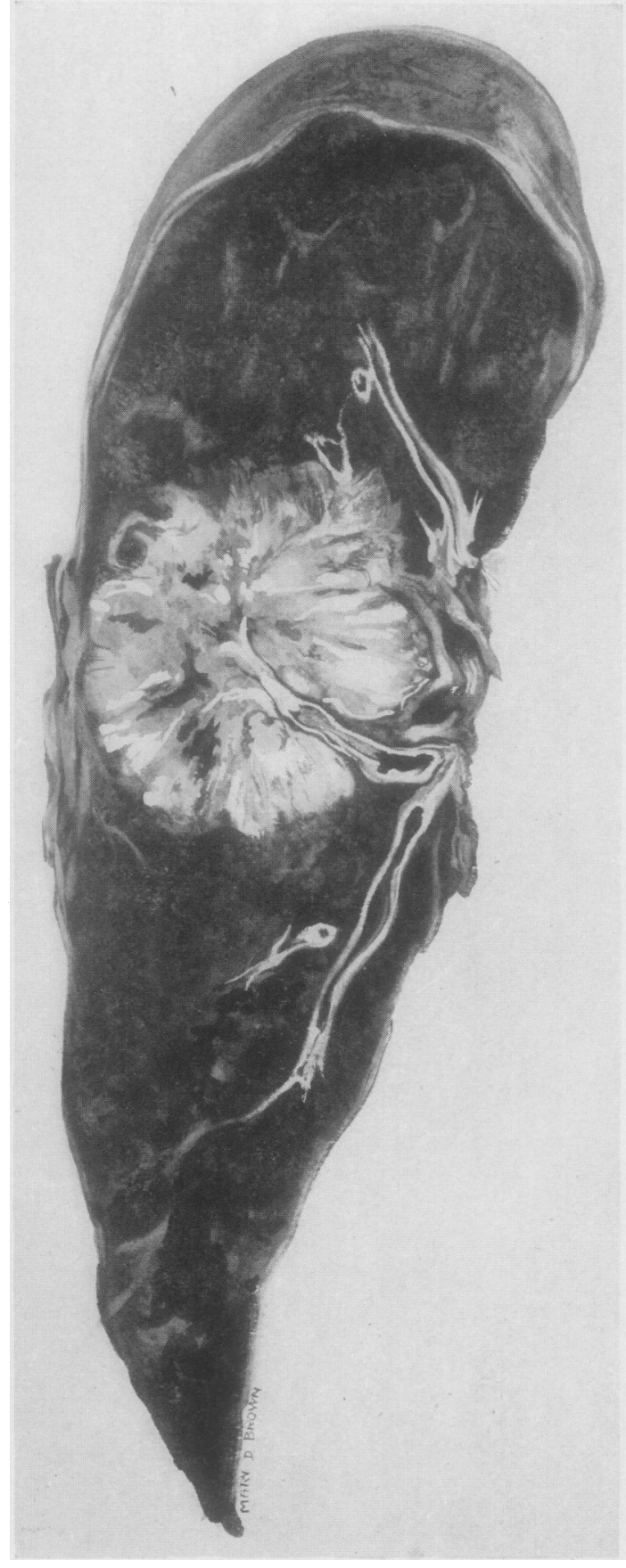

FIG. 12. - Right upper lobectomy specimen. Peripheral tumour entering a vein. Subsequent cerebral metastasis. involves the auricle directly (Fig. 8 ), thus rendering surgery impossible ; but when slightly more peripheral, resection may be completed, though a pessimist would judge this hardly worth while. However, one patient remains free from recurrence two and a half years after a resection, including part of the left auricle, for such an extension (Fig. 9). In another patient a mushroom of growth within the inferior pulmonary vein (Fig. 10) was felt as soon as the pericardium was opened; this was immediately isolated from the general circulation, and the patient remains well over a year later. $\mathrm{He}$ is now past the period when generalized deposits most frequently appear. Fig. 11 shows a hidden gross vein destruction buried in the midst of a tumour resected by the usual method; this resulted in widespread metastases and death nine months later. Had this situation been realized at operation, primary vein ligation would have been irresistible, if indeed resection was still thought worth while.

Peripheral tumours have a bad reputation and commonly cause distant spread ; Fig. 12 shows such a tumour with a cord of intravenous growth extending from it. This man was young, and after lobectomy he had six months' freedom from mediastinal spread, but he developed cerebral metastases from which pneumonectomy would not have saved him ; with ligation of the veins first those few vital cells reaching the cerebral circulation might have remained in the specimen. 


\section{Massive Malignant Emboli}

Clinical silence hampers the detection of vascular spread at its onset, but occasionally large fragments of growth are broken off into the circulation during pneumonectomy. This complication, though rare, is dramatic and usually fatal, but may be preventable. Two such cases have been observed at Leeds, and, in discussion at a recent meeting of the Society of Thoracic Surgeons of Great Britain and Ireland additional cases were reported by other speakers.

Case 1.-A 37-year-old housewife was seen with a large tumour in the right lung (Fig. 13). This was secondary to a fibrosarcoma of the back, which had recurred locally after three separate removals spaced over 15 years. Pneumonectomy offered the only chance of survival. The resection was difficult, the hilum being so obscured by the tumour that the structures there were dealt with in the following order: the bronchus was clamped, the pulmonary artery divided inside the pericardium, then the anterior pulmonary vein; the bronchus had to be divided to aid exposure of the inferior pulmonary vein, which was removed with part of the left auricle. Her condition deteriorated rapidly after operation, and she died, without regaining consciousness, five hours later.

Necropsy revealed a large recent malignant embolus $7 \mathrm{~cm}$. long in the lower half of the abdominal aorta and its bifurcation, with a similar fragment blocking the coeliac axis. The stomach, liver, and intestines were infarcted, though the brain was normal.

Case 2.-A man aged 52 was submitted to pneumonectomy for a large right upperlobe tumour (Fig. 14), which felt fluctuant in places and was dull red where it lay under the pleura. The pericardium was opened, and after division of the inferior pulmonary vein the anterior pulmonary vein was being divided when a fragment of growth oozed from the lumen between the ligatures. It was attached to the pulmonary side, and though the proximal ligature was placed first the patient's breathing become jerky and uncontrollable, and the right radial pulse disappeared, but the subclavian pulse was good when palpated inside the chest. His condition after closure was unsatisfactory, and did not improve after bronchoscopy, at which a loose fragment of tumour was removed from the left lower-lobe bronchus, where it had lodged in spite of a Thompson blocker. He died 10 hours later with signs of a right-sided cerebral catastrophe and embolism of the right axillary artery.

At necropsy a suspension of red lead injected into the innominate artery followed by $x$-ray examination demonstrated arterial blockage in the positions indicated by clinical examination (Figs. 15 and 16). Section of the right lung showed a soft growth mixed with haematoma arising from malignant erosion of a pulmonary artery (Fig. 17). A large branch of the anterior pulmonary vein was also eroded (Fig. 18), and contained the same kind of gelatinous growth and clot as that which blocked the middle cerebral artery (Fig. 19). The full situation was exposed only when the abdomen was examined, for here, on the greater curvature of the stomach, was a highly cellular tumour (Fig. 20) from which radiated hard veins full of growth. These were responsible for all the fine intrahepatic portal radicles being filled with soft malignant sludge (Fig. 21 ), scarcely noticeable on the surface of the liver, for there were none of the discrete metastases usually associated with secondary spread.

Professor Willis examined these tumours, and considered the gastric one secondary to the larger anaplastic bronchial carcinoma. 


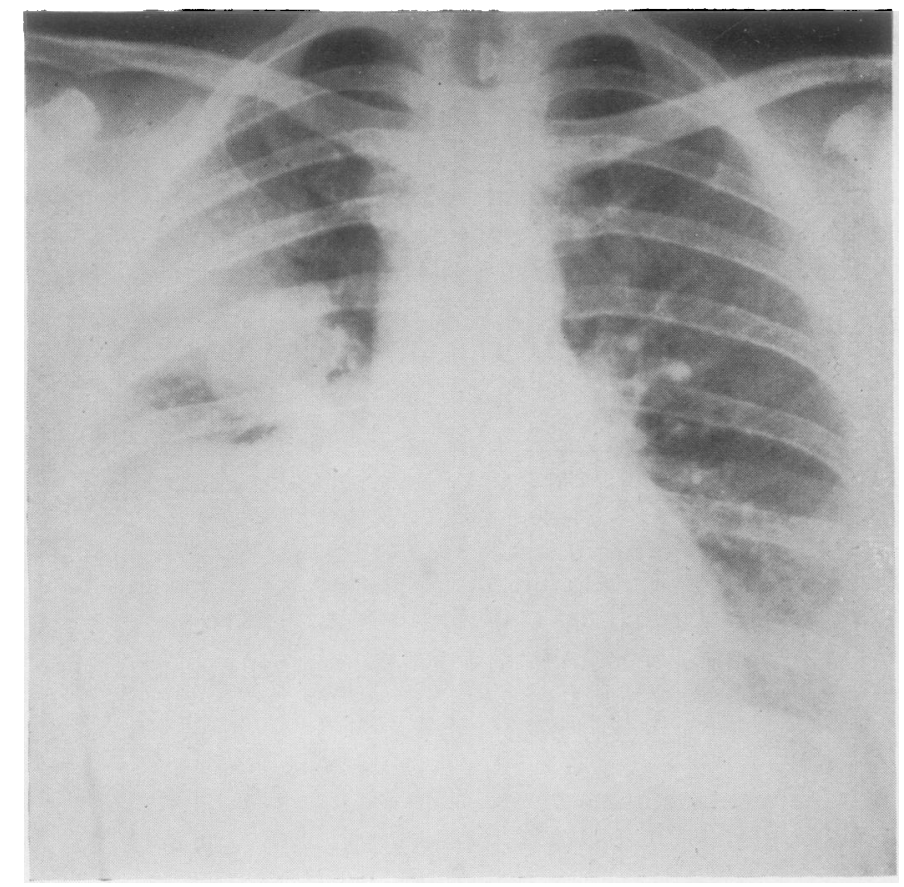

FIG. 13a

Fig. 13.-Large secondary fibro-sarcoma in right lower lobe (Case 1).

FIG. $13 b$ 


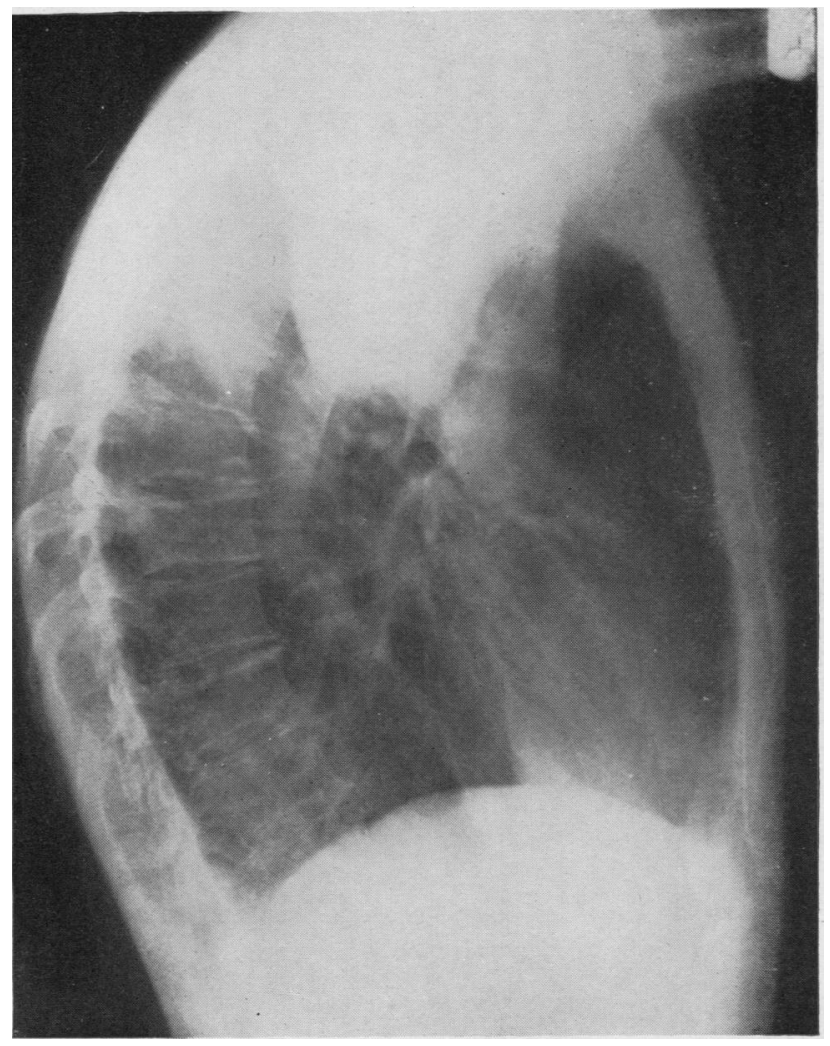

Fig. 14.-Right upper lobe tumour (Case 2).

\section{FIG. 14a}

FIG. 14b

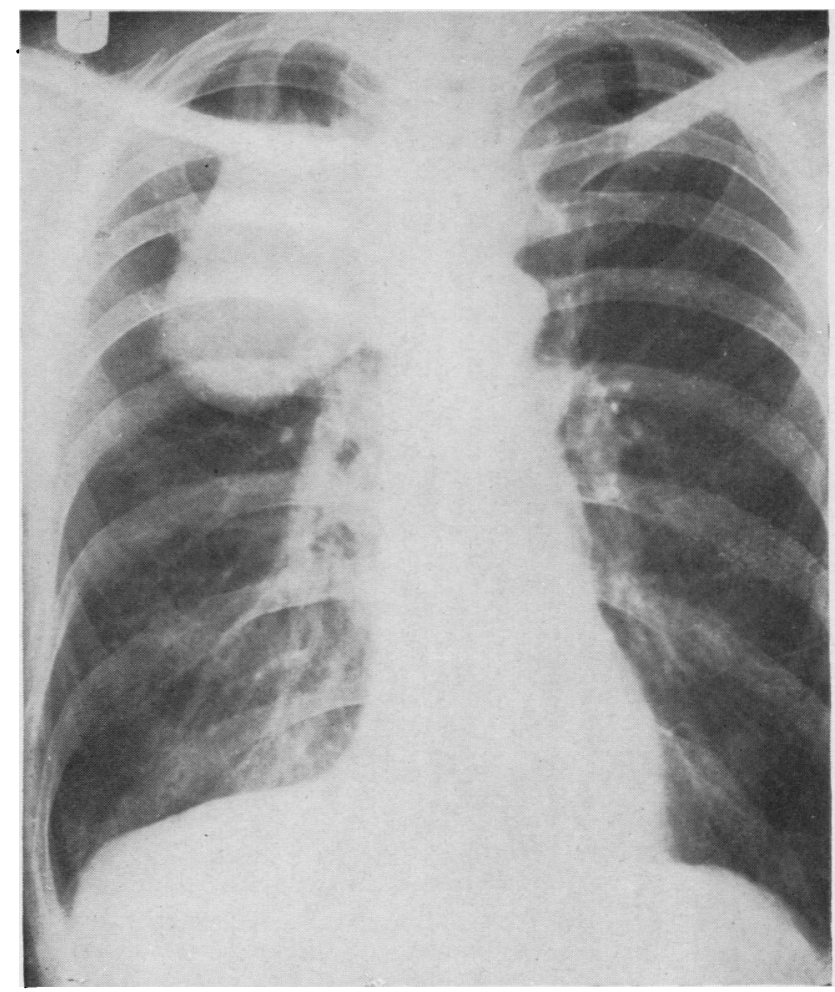

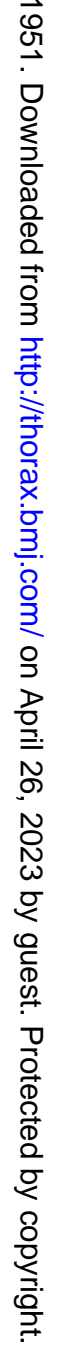




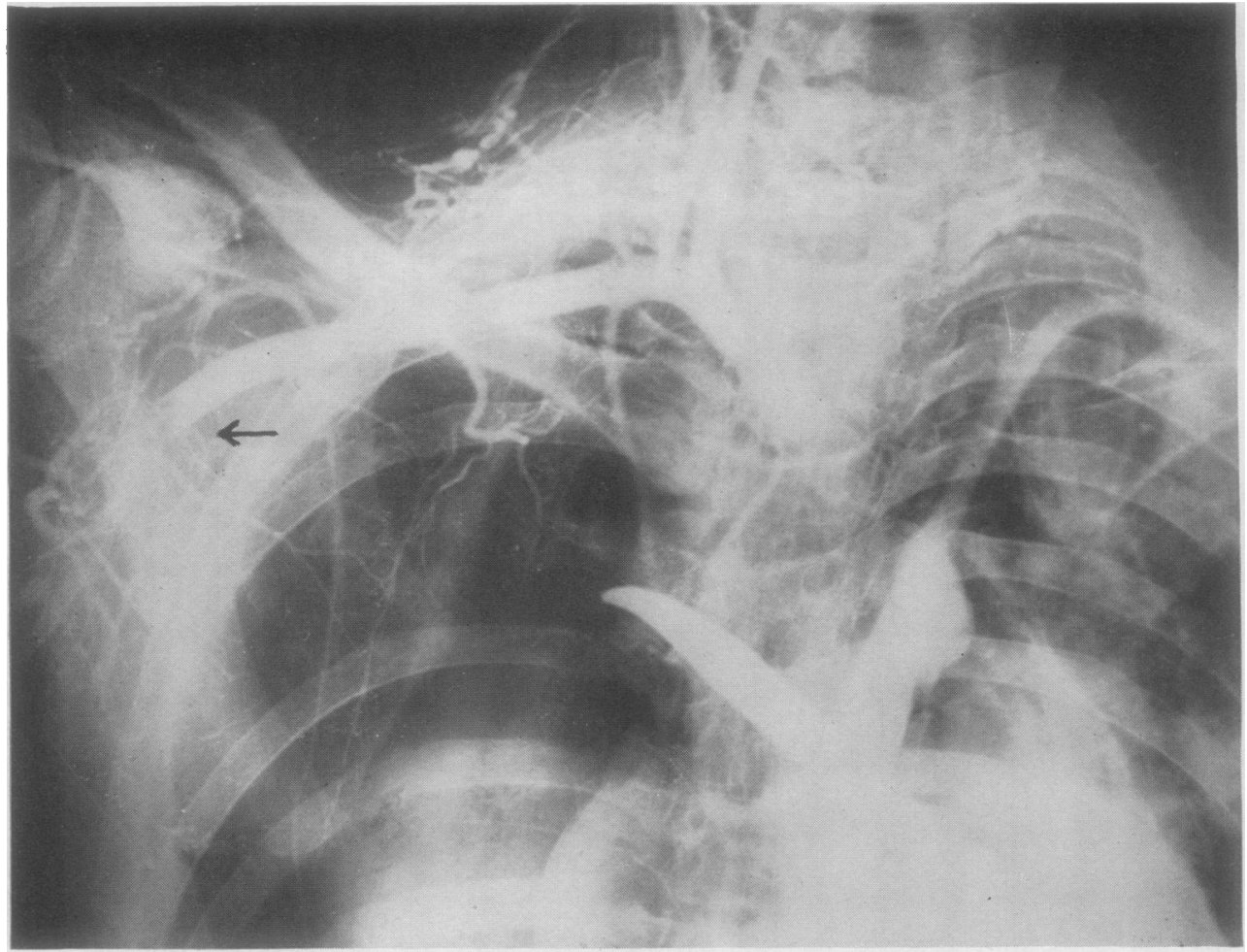

Fig. 15.-Malignant embolus in right axillary artery shown by post-mortem injection (Case 2).

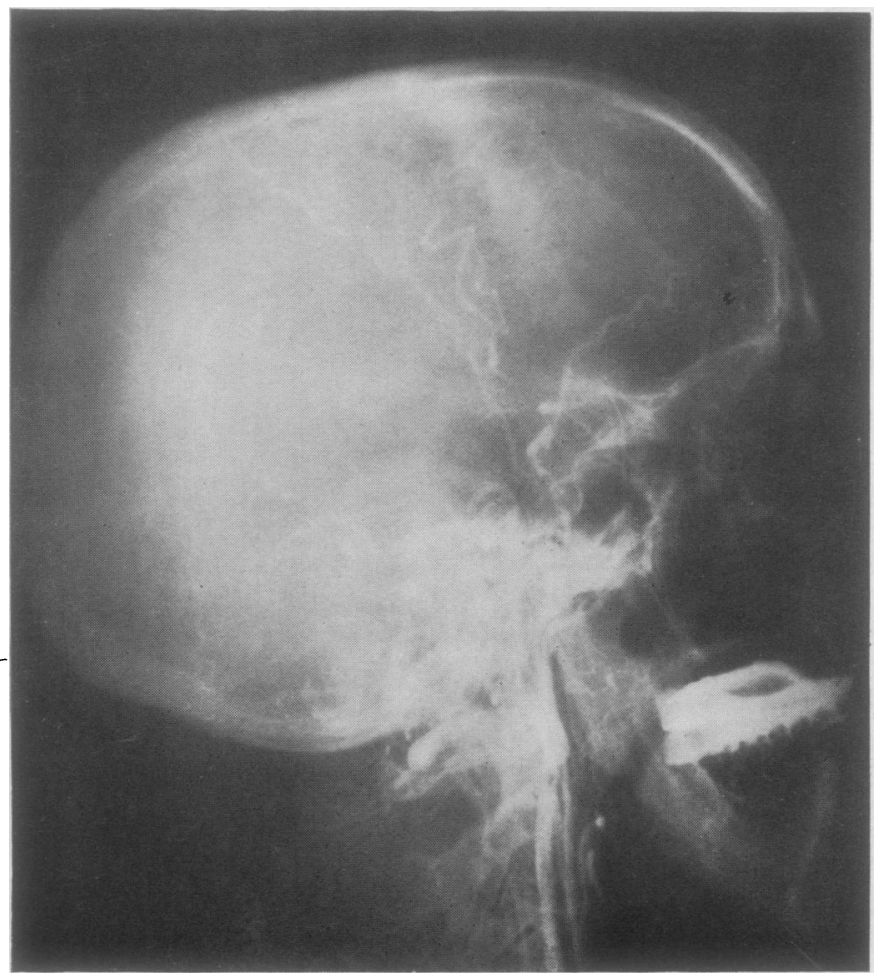

FIG. 16.-Internal carotid artery blocked at base of the skull, but branches of the external carotid outlined by post-mortem injection (Case 2). 


\section{Discussion}

It is not difficult to demonstrate that vein invasion is common, if not universal, in bronchial carcinoma, and carries a poor prognosis. After resection $80 \%$ of such patients die rapidly with generalized deposits when none are suspected at the time of operation. Excluding three patients with palliative resections dying from early local recurrence, only three out of 32 known to have vein invasion have remained well more than one year, and of these one had the involved vein tied first; all the remainder had widespread metastases. Most pathologists believe that distant spread is inevitable once the veins are invaded, and this implies that $60 \%$ of these resections were beyond the scope of surgical cure before operation, but the truth of this assumption must be put to the test before it is taken for granted. Not all distant spread can be avoided by tying veins first, but there is a logical case for hoping that some will, for few tumours can be removed without squeezing them, and careful histological examination shows that malignant material is usually available for vascular dispersal. On every occasion it seems advisable habitually to take precautions against contaminating the general circulation during resection, just as other forms of spill are avoided wherever possible. Even when surrounded by growth, the main veins are not as commonly eroded as their smaller side branches. They have thicker muscular walls and plentiful vasa vasorum, which

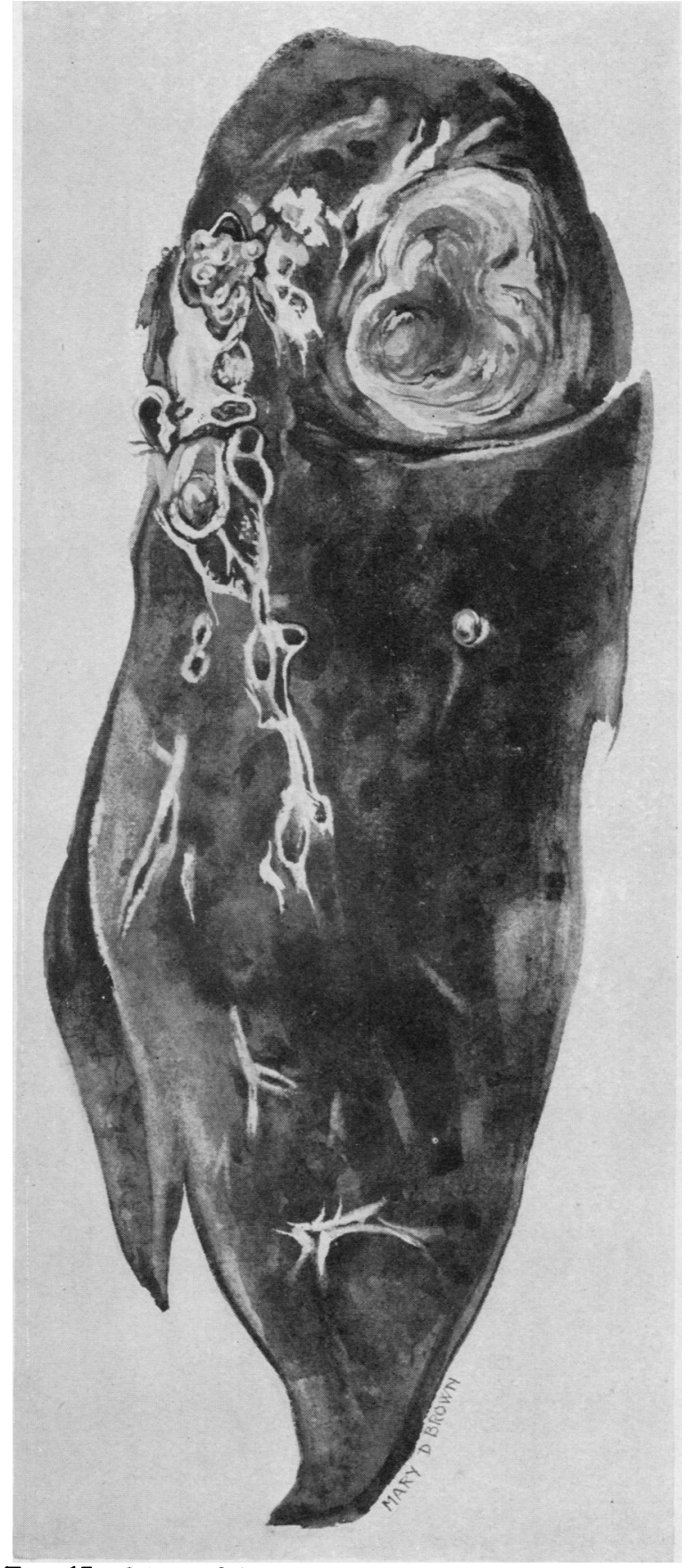

Fig. 17.-Mass of intravascular tumour and haematoma formation in primary, due to both arterial and venous
erosion (Case 2). 
Fig. 18.-Tumour tissue in anterior pulmonary veins (Case 2).
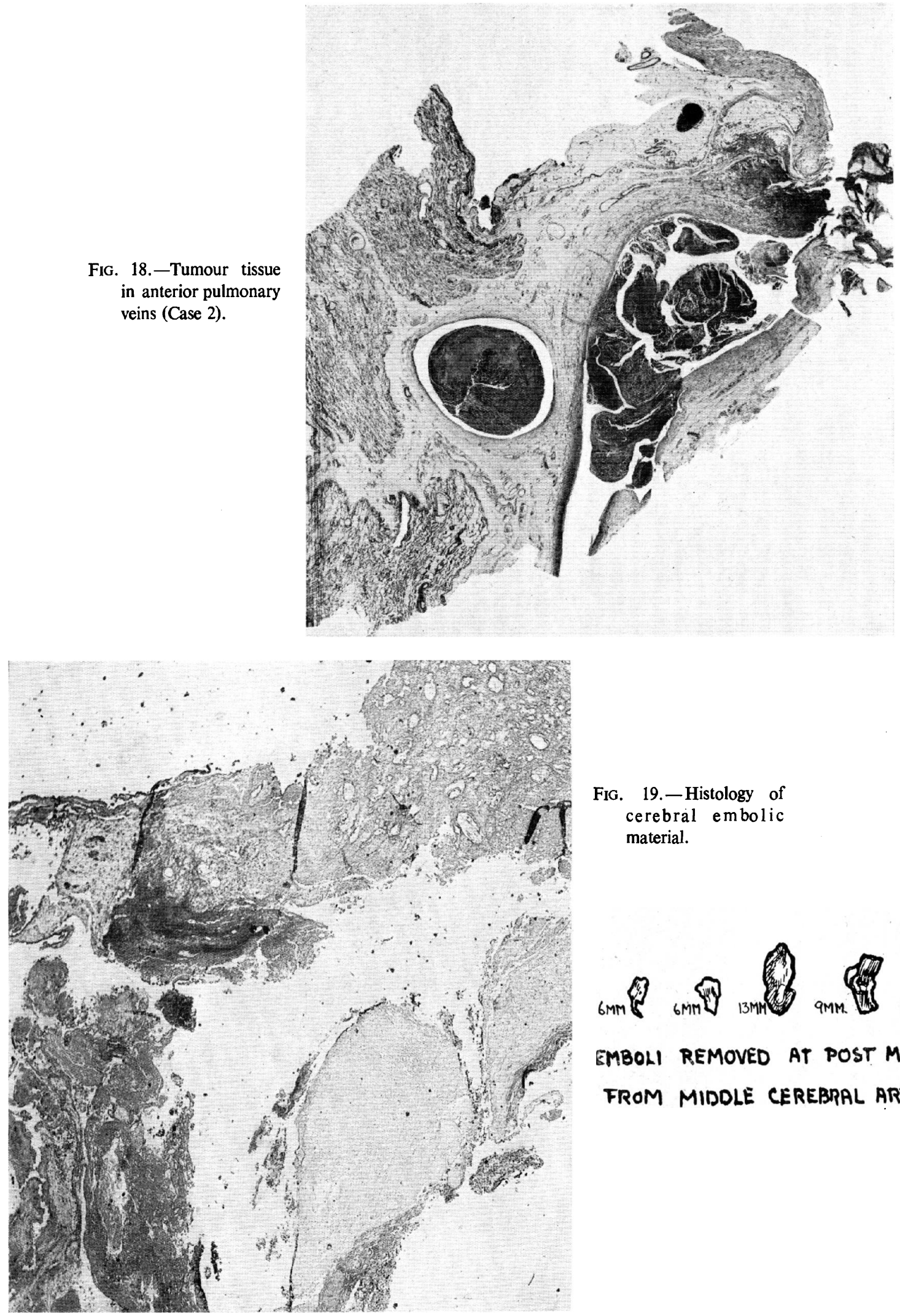

FIG. 19.- Histology of cerebral embolic material. 
seem to produce a better developed tissue reaction when attacked by carcinoma, thus appearing to share with the pulmonary arteries a relative resistance to erosion. The commoner small vein erosions are less conspicuous but equally important, for it is known that peripheral tumours are often associated with widespread metastases, so they too should have their venous drainage isolated as soon as possible.

Results.-A follow-up of patients after resection leaves no clue as to when seedling metastases were released. If death occurs from immediate surgical complications, post-mortem examination sometimes discloses quite large, but unsuspected, deposits. The frequency of these, in the majority who survive operation, is not known, and even with a detailed examination of large series of early post-operative necropsies not all established deposits would be recognized. Without a practical method for determining the presence of all minute emboli in the body at the time of resection it is impossible to apportion vascular recurrences to either pre-operative or operative spread, so the value of vein ligation can be determined only by follow-up results. However, the Leeds series shows a mortality curve from vascular deposits with a sharp peak at the fifth month (Fig. 22) suggesting a cause-and-effect relation-

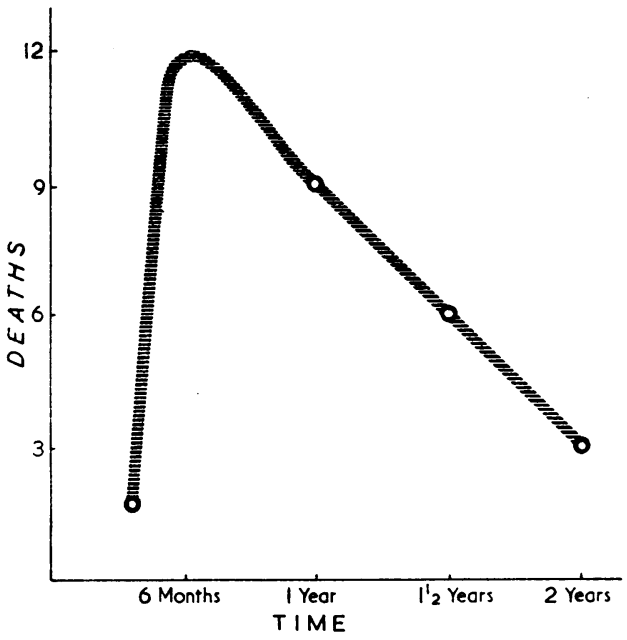

FIG. 22.-Graph showing the time after operation when vascular metastases cause death. ship. And if this curve becomes flattened in a significant series where the veins have been tied first, the value of this step will be established one year after a sufficient number of ligations have been completed. It is interesting to note that Neuhof and Aufses (1948) show a first-year mortality graph with two peaks (at six months and 12 months). The explanation of this is suggested in Fig. 1, where vascular spread and local recurrence have been separated.

When examining ve:ns attacked by carcinoma, the tissue reaction about them seemed to vary with the tumour concerned, and was strikingly deficient in the oat-cell types, which are the commonest tumours in the invaded group (Table III). This diminished, and possibly inhibited, "defence mechanism" may be a basis for the special capacity of this growth to produce distant spread, and a knowledge of its cause may prove to be valuable.

The second case of massive malignant embolism draws attention to cancer erosion of the portal system from the stomach, which may be responsible for bad results of radical surgery in gastric carcinoma.

Spaeth (1866) first described this process, the importance of which was emphasized by Willis (1930). There may be a good case for tying the gastric veins first when resecting the stomach through a thoraco-abdominal incision, which lends itself to tying the left gastric and splenic veins early as the spleen and pancreas are lifted forwards (the other veins being always available at the pylorus). Investigation of the incidence of vein invasion in gastric carcinoma specimens should not present much difficulty and will provide useful and interesting information. 
TABLE III

ANalysis of 57 Slides Showing Variety of Tumour with and without Venous INVASION

\begin{tabular}{|c|c|c|c|c|}
\hline & & Oat Cell & Squamous & Miscellaneous \\
\hline Invasion found ( 23 cases) $\ldots$ & . & $56 \%$ & $34 \%$ & $10 \%$ \\
\hline Invasion not found ( 35 cases) & .. & $28 \%$ & $54 \%$ & $18 \%$ \\
\hline
\end{tabular}

Technique.-In practice, tying pulmonary veins first may add time to a resection more easily accomplished by the usual method of taking the simple structures first and leaving the veins to the end. If the access is difficult, dividing both veins after the pericardium is opened on either side of the lung root often helps, or it is usually possible to place a ligature on the vein without necessarily dividing it at this stage. This is an advantage if further dissection reveals unsuspected inoperability, for then the ligature can be removed without risk of gangrene. Also it may be difficult to decide which vein to tie, especially when the tumour lies midway between them where anomalous branches are common, but nothing untoward occurs when both are tied, even if subsequent delay in securing the pulmonary artery has resulted in some engorgement of the lung. The loss of circulating blood volume is not great, and is readily replaced without detriment to the patient. The method of approach to the involved vein must be modified in each case according to the circumstances found when the thorax is opened, and the choice is based on wholly avoiding manipulation.

\section{SUMMARY}

The erosion of veins in bronchial carcinoma is both common and serious, and contamination of the general circulation at operation should be anticipated by tying the veins inside the pericardium before manipulating the tumour. Without this modification in technique it is wrong to assume that all subsequent vascular deposits are unavoidable.

Massive malignant emboli during pneumonectomy are rare, but two cases are described, and grounds are discussed for believing that smaller ones may be frequent but pass unrecognized.

In gastric carcinoma it is possible that a similar process occurs in the portal circulation, where preventive action is simple with the thoraco-abdominal approach.

In both bronchial and gastric carcinoma the results of surgery need improvement in spite of radical resection, and the importance of vascular spread has been neglected in planning surgical technique.

I should like to thank Professor Willis for examining the tumours in Case 2, and Mr. Allison for every help and encouragement.

\section{REFERENCES}

Allison, P. R. (1946). J. thorac. Surg., 15, 99.

Boyd, W. (1930). Canad. med. Ass. J., 23, 210.

Fried, B. M., and Buckley, R. C. (1930). Arch. Path., Chicago, 9, 483.

Goldmann, E. (1897). Beitr. klin. Chir., 18, 595.

Neuhof, H., and Aufses, A. H. (1948). J. thorac. Surg., 17, 297.

Rienhoff, W. F. (1947). Ann. Surg., 125, 541.

Simpson, S. L. (1929). Quart. J. Med., 22, 413.

Spaeth, E. (1866). Virchows Arch., 35, 432.

Willis, R. A. (1930). J. Path. Bact., 33, 849.

- (1934). Spread of Tumours in the Human Body, pp. 19, 51. London.

- (1948). Pathology of Tumours, p. 374. London. 